\title{
LAYANAN BIMBINGAN KELOMPOK DALAM MENGATASI KECEMASAN BELAJAR MATEMATIKA SISWA
}

Oleh:

\author{
Darmayanti $^{1)}$, Sudarmi Suud Binasar ${ }^{2)}$ \\ 1) 2) Jurusan Bimbingan dan Konseling \\ Fakultas Keguruan dan Ilmu Pendidikan, Universitas Halu Oleo \\ Email: darmaquincy@gmail.com
}

\begin{abstract}
ABSTRAK
Penelitian ini bertujuan untuk mengatasi kecemasan belajar Matematika siswa kelas VIII.7 SMP Negeri 10 Kendari melalui layanan bimbingan kelompok. Subjek dalam penelitian ini berjumlah 8 siswa. Jenis penelitian ini adalah penelitian kuantitatif pra eksperimen dengan desain one group pre test and post test. Data dikumpulkan dengan menggunakan Skala Kecemasan Belajar Matematika. Hasil Penelitian menunjukan bahwa layanan bimbingan kelompok dapat mengatasi kecemasan belajar Matematika, hal ini berdasarkan skor kecemasan Matematika siswa dari 151,375 menjadi 131,75 atau 7,36\% berada pada kategori rendah. Sedangkan hasil uji hipotesis dengan menggunakan uji Wilcoxon Signed Rank Test pada taraf signifikan $\alpha=0.05$ diperoleh Pvalue $=0.012$. Pvalue $<\alpha(0.012<0.05)$. Dengan demikian hipotesis Ha diterima dan hipotesis Ho ditolak. Maka dapat disimpulkan bahwa layanan bimbingan kelompok dapat mengatasi kecemasan belajar Matematika siswa SMP Negeri 10 Kendari.
\end{abstract}

Kata Kunci: Kecemasan belajar Matematika, Bimbingan Kelompok

\section{GROUP GUIDANCE SERVICES IN OVERCOMING STUDENTS MATHEMATICS ANXIETY}

\begin{abstract}
The objective of research was to deal with the student mathematics learning anxiety, particularly to the VIII.7 Graders of the Public Junior High School 10 Kendari. The subjects of the study were 8 students. This was pre experimental quantitative research with one pre test and post test design. Data were collected using the Mathematical Learning Emergency Scale. The findings of the research show that group guidance service is able to deal with the mathematics learning anxiety is decreasing from 151,375 to 131,75 . It decline $7,36 \%$ of the total grades. Based on the result of hypothesis test using Wilcoxon Signed Rank Test, it was foumd that it's significant was $\alpha=0,05$ with its Pvalue $=0.012$. Pvalue $<\alpha(0.012<0.05)$. The test result indicates that Ha is accepted and Ho is rejected. The result can therefore be concluded the group quidance service is able to deal with the students mathematics learning anxiety of the Public Junior High School 10 kendari.
\end{abstract}

Keywords: Mathematics Anxiety, Group Guidance 


\section{Pendahuluan}

Matematika merupakan salah satu mata pelajaran yang diajarkan di lembaga pendidikan. Matematika diajarkan baik di Sekolah Dasar (SD), Sekolah Menengah Pertama (SMP), Sekolah Menengah Atas (SMA) hingga Perguruan Tinggi. Matematika memegang peranan yang amat besar dalam pengembangan ilmu teknologi dan informasi maupun dalam kehidupan sehari-hari. Menurut May dkk. (2008: 44-45) kehadiran Matematika secara meluas dapat dirasakan manfaatnya dalam setiap aspek kehidupan modern. Mulai dari melakukan pengukuran apapun, membuat bangunan, menggunakan uang, persoalan ekonomi, politik dan sosial.

Usaha dalam mengajarkan Matematika tidak selalu sama dengan hasil yang dicapai. Dalam proses pembelajaran Matematika sering dijumpai hambatan yang muncul baik dari dalam diri siswa maupun dari lingkungan sekitar atau bahkan dari Matematika itu sendiri, mengingat Matematika adalah mata pelajaran yang bersifat logis, sistematis dan penuh dengan lambang serta rumus yang terkadang membingungkan. Siswa yang belum memahami materi ataupun rumus Matematika akan merasa kurang percaya diri ketika menghadapi mata pelajaran Matematika, baik ketika belajar ataupun mengerjakan soal-soal Matematika yang menyebabkan munculnya perasaan takut dan tegang. Perasaan takut dan tegang dalam menghadapi sesuatu ini sering disebut sebagai kecemasan. Nawangsari (dalam Handayani, 2016: 27) menjelaskan bahwa kecemasan adalah suatu kondisi yang tidak menyenangkan meliputi rasa takut, rasa tegang, khawatir, bingung dan tidak suka yang timbul karena adanya perasaan tidak aman terhadap bahaya yang diduga akan terjadi. Kaitannya dengan mata pelajaran Matematika, Anita (2014: 126) mengemukakan bahwa kecemasan yang dialami siswa pada mata pelajaran Matematika sering disebut sebagai kecemasan Matematika (mathematics anxiety).

Yusof dan Tall (dalam Syafri, 2014: 60) mengemukakan bahwa sikap negatif terhadap Matematika biasanya muncul ketika siswa memiliki pengalaman buruk pada saat kesulitan dalam menyelesaikan soal atau ketika ujian, jika kondisi ini terjadi secara berulang-ulang maka sikap negatif tersebut akan berubah menjadi kecemasan Matematika. Ashcraft (dalam Mammarella, Caviola dan Dowker, 2018: 1) mendefinisikan kecemasan Matematika sebagai " $a$ feeling of tension and anxiety that interferes with the manipulation of number and the solving of mathematical problems in a wise variety of ordinary life and academic situations" perasaan tegang dan cemas yang menggangu manipulasi angka dan penyelesaian masalah Matematika dalam berbagai kehidupan sehari-hari dan situasi akademik.

Dzulfikar yang mengadaptasi dari Cooke (dalam Syafri, 2017: 62) mengemukakan indikator kecemasan Matematika terdiri dari 4 komponen yaitu: 1) Mathematics knowledge/ understanding, berkaitan dengan hal-hal seperti munculnya pikiran bahwa dirinya tidak cukup tahu tentang Matematika. 2) Somatic, berkaitan dengan perubahan pada keadaan tubuh seseorang misalnya tubuh berkeringat atau jantung berdebar cepat. 3) Cognitive, berkaitan dengan perubahan pada kognitif seseorang ketika berhadapan dengan Matematika, seperti tidak dapat berpikir jernih atau menjadi lupa hal-hal yang biasanya dapat ia ingat. 4) Attitude, berkaitan dengan sikap yang muncul ketika seseorang memiliki kecemasan Matematika, misalnya ia tidak percaya diri untuk melakukan hal yang diminta atau enggan untuk melakukannya.

Kecemasan belajar Matematika seperti ciriciri di atas juga dijumpai di Sekolah Menengah Pertama Negeri 10 Kendari. Berdasarkan hasil wawancara dengan salah satu guru Matematika kelas VIII bahwa ada beberapa siswa yang terlihat tegang pada saat proses pembelajaran Matematika berlangsung, terlihat tidak percaya diri pada saat diminta untuk mengerjakan soal latihan di papan tulis dan ada siswa yang terkadang meminta izin ke kamar kecil dan kembali saat pelajaran Matematika akan selesai. Hal ini juga didukung dengan hasil angket screening kecemasan belajar Matematika yang telah dibagikan kepada siswa kelas VIII.7 menunjukan bahwa terdapat 5 siswa dengan skor tinggi.

Kecemasan terhadap mata pelajaran Matematika tidak bisa dipandang sebagai hal biasa, karena ketidakmampuan siswa dalam beradaptasi pada pelajaran Matematika menyebabkan siswa kesulitan dalam memahami materi pelajaran, membuat siswa tidak mampu menyelesaikan soalsoal dan kemudian menghindari kelas Matematika, dan pada akhirnya menyebabkan hasil belajar dan prestasinya menurun.

Dalam layanan bimbingan dan konseling terdapat berbagai macam layanan yang dapat dilakukan untuk mengatasi masalah siswa seperti masalah di atas yaitu kecemasan belajar 
Matematika, salah satunya adalah layanan bimbingan kelompok. Menurut Hartinah (2009) layanan bimbingan kelompok adalah bantuan kepada individu dalam situasi kelompok yang bertujuan untuk meningkatkan pemahaman dan penerimaan terhadap nilai-nilai dan tujuan tertentu, mempelajari ataupun menghilangkan perasaanperasaan, sikap atau perilaku yang tidak tepat. Dengan cara memberikan materi dan memanfaatkan dinamika kelompok.

Melalui layanan bimbingan kelompok, siswa yang mengalami kecemasan belajar Matematika karena memiliki pikiran-pikiran negatif terhadap mata pelajaran Matematika yang disebabkan pengalaman yang buruk tentang Matematika akan mendapatkan pemahaman yang baru tentang Matematika, serta materi-materi terkait pentingnya belajar Matematika. Pemahaman yang baru ini diharapkan dapat menghilangkan pikiran-pikiran negatif siswa tentang Matematika. Selain itu siswa yang mengalami kecemasan Matematika karena tidak mampu memahami materi ataupun rumus dapat menerima tips belajar Matematika yang menyenangkan dari anggota kelompok lainnya sehingga dapat mengurangi kecemasan dan meningkatkan kepercayaan diri siswa pada saat belajar ataupun mengerjakan soal latihan di depan kelas.

Dengan pemberian layanan bimbingan kelompok ini diharapkan dapat mengatasi kecemasan Matematika pada siswa. Berdasarkan penjelasan di atas peneliti tertarik untuk melakukan penelitian dengan judul "Layanan Bimbingan Kelompok dalam Mengatasi Kecemasan Belajar Matematika Siswa SMP Negeri 10 Kendari". Tujuan penelitian ini adalah untuk mengetahui apakah layanan bimbingan kelompok dapat mengatasikecemasan belajar Matematika pada siswa SMP Negeri 10 Kendari.

Kecemasan Matematika menurut Ashcraft (dalam Mammarella, Caviola dan Dowker, 2018: 1) adalah " a feeling of tension and anxiety that interferes with the manipulation of number and the solving of mathematical problems in a wise variety of ordinary life and academic situations" perasaan tegang dan cemas yang menggangu manipulasi angka dan penyelesaian masalah Matematika dalam berbagai kehidupan sehari-hari dan situasi akademik.

Berdasarkan pengertian tersebut, dapat disimpulkan bahwa kecemasan Matematika adalah rasa takut, khawatir, tegang dan cemas ketika menghadapi mata pelajaran Matematika, diakibatkan oleh beberapa hal yang dapat mengganggu kinerja Matematika.

Feiberg (dalam Whyte dan Anthony,2012) juga mengemukakan bahwa kecemasan Matematika dapat memengaruhi individu dengan berbagai cara seperti memicu reaksi kognitif, afektif dan fisik. Reaksi kognitif melibatkan selftalk negatif atau munculnya pikiran-pikiran negatif, pikiran menjadi kosong (blank) dan penghindaran. Reaksi afektif yang ditandai oleh ketidakpercayaan kemampuan, takut terlihat bodoh dan kehilangan harga diri dan reaksi fisik yang dapat dibuktikan dengan badan berkeringat, meningkatnya denyut jantung, mengalami ketegangan dan mual.

Menurut Smith (dalam Yani, Kumar, dan Syukri, 2015) ciri-ciri kecemasan belajar Matematika yaitu:

1. Khawatir saat diminta melakukan penyelesaian masalah secara matematis.

2. Menghindari kelas Matematika.

3. Merasakan pusing, takut atau panik.

4. Ketidaksanggupan untuk mengikuti tes Matematika.

5. Penggunaan tutor sebaya atau sesi diskusi kurang berhasil.

Berdasarkan ciri-ciri dari kecemasan belajar Matematika menurut para ahli di atas dapat disimpulkan bahwa ciri-ciri kecemasan Matematika dapat dilihat dari mathematics understanding (pemahaman Matematika) yang meliputi perasaan tidak cukup tahu tentang Matematika, somatic (somatik) atau keadaan fisik yang memperlihatkan gejala-gejala seperti badan berkeringat jantung berdebar cepat mengalami ketegangan dan merasa mual, kognitive (kognitif) yang meliputi gejala-gejala seperti menjadi lupa hal-hal yang biasanya dapat diingat, munculnya pikiran-pikiran negatif dan penghindaran dan afektif yang meliputi attitude (sikap) seperti tidak percaya diri untuk melakukan hal yang diminta, enggan untuk melakukan kegiatan yang berhubungan dengan Matematika, takut terlihat bodoh dan kehilangan harga diri.

Denhere, Olaniyan dan Salman (dalam Anditya, 2016: 10-15) menyebutkan faktor-faktor penyebab kecemasan Matematika pada siswa antara lain yaitu:

1. Kondisi kelas yang kurang kondusif membuat siswa kesulitan memahami materi pelajaran, sehingga berdampak pada pemahaman siswa yang rendah. Pemahaman yang rendah akan 
membuat siswa merasa khawatir tidak mampu mengerjakan soal-soal Matematika. Kekhawatiran yang dirasakan siswa akan memicu timbulnya kecemasan Matematika.

2. Ujian nasional Matematika yang diadakan setiap tahun dapat menimbulkan kecemasan terhadap Matematika ketika siswa belum menguasai materi pelajaran Matematika.

3. Matematika memiliki banyak rumus, siswa merasa kesulitan untuk memahami rumusrumus Matematika.

4. Harapan dari keluarga agar mendapat nilai yang bagus. Ketika keluarga menginginkan agar siswa mendapatkan nilai Matematika yang bagus, sementara di sisi lain siswa tersebut kurang menguasai materi pelajaran Matematika, maka akan membuat siswa merasa tertekan sehingga bisa menyebabkan kecemasan terhadap Matematika pada diri siswa.

5. Siswa tidak bisa menyelesaikan permasalahan Matematika. Berdasarkan pengalaman siswa ketika kesulitan dalam mengerjakan soal-soal Matematika, menyebabkan siswa berpandangan bahwa Matematika itu sulit. Jika pandangan tersebut telah menjadi mindset siswa, maka kecemasan Matematika akan timbul pada diri siswa tersebut.

Trujillo dan Hadfield (dalam Anita, 2014: 127-128) juga mengemukakan bahwa faktor-faktor kecemasan terhadap Matematika ada tiga yaitu:

1. Faktor kepribadian (psikologis atau emosional) merupakan faktor dari dalam diri siswa, misalnya perasaan takut siswa akan kemampuan yang dimilikinya (self-efficacy belief), kepercayaan diri yang rendah yang menyebabkan rendahnya nilai harapan siswa (expectancy value), motivasi diri siswa yang rendah dan sejarah emosional seperti pengalaman tidak menyenangkan di masa lalu yang berhubungan dengan Matematika yang menimbulkan trauma.

2. Faktor lingkungan atau sosial merupakan faktor dari luar diri siswa, misalnya kondisi saat proses belajar mengajar Matematika di kelas yang tegang diakibatkan oleh cara mengajar, model dan metode mengajar guru Matematika. Rasa takut dan cemas terhadap Matematika dan kurangnya pemahaman yang dirasakan para guru Matematika dapat terwariskan kepada para siswanya. Faktor yang lain yaitu keluarga terutama orang tua siswa yang terkadang memaksakan anak-anaknya untuk pandai dalam
Matematika karena Matematika dipandang sebagai sebuah ilmu yang memiliki nilai prestise.

3. Faktor intelektual, faktor intelektual terdiri atas pengaruh yang bersifat kognitif, yaitu lebih mengarah pada bakat dan tingkat kecerdasan yang dimiliki siswa.

Faktor kepribadian seperti kepercayaan diri yang rendah juga dikemukakan oleh Wigfield dan Mecce (dalam Hartatik dan Fitriyah, 2017: 31) yang menjelaskan bahwa penyebab kecemasan terhadap pelajaran Matematika adalah ketidakpercayaan diri dalam menyelesaikan soal Matematika dan memiliki emosi negatif terhadap soal-soal Matematika.

Selanjutnya faktor pengalaman, metode mengajar dan keluarga juga dikemukakan oleh Kidd (dalam Aunurrofiq dan Junaedi, 2017: 159) yang mengungkapkan bahwa kecemasan matematik yang dialami siswa dapat disebabkan oleh anggapan dasar tentang Matematika itu sendiri, pengalaman pembelajaran di kelas, cara pengajaran dan keluarga.

\section{Metode Penelitian}

Penelitian ini dilaksanakan di SMP Negeri 10 Kendari, Jl. Prof. Dr. Abdurrauf Tarimana, Kecamatan Kambu, Kota Kendari. Alasan pemilihan tempat pelaksanaan penelitian ini didasarkan atas beberapa pertimbangan tertentu. Pertimbangan pertama adalah adanya masalah terkait kecemasan belajar Matematika dimana masalah ini memberikan dampak yang buruk terhadap prestasi belajar siswa. Pertimbangan kedua adalah keterjangkauan lokasi penelitian oleh peneliti baik dilihat dari segi tenaga, dana maupun segi efisiensi waktu.

Penelitian ini dilaksanakan selama 3 bulan yakni pada bulan Desember 2018 sampai bulan Maret 2019. Pemberian Treatment yaitu Layanan Bimbingan Kelompok dilaksanakan selama 6 kali pertemuan dengan frekuensi pertemuan dua kali dalam seminggu dengan durasi waktu tiap pertemuan selama 2 x 45 menit.

Penelitian ini merupakan penelitian kuantitatif dengan metode pra eksprimen. Penelitian pra eksperimen merupakan penelitian eksperimen yang dilakukan dengan tanpa melakukan pengendalian terhadap variablevariabel yang berpengaruh. Dalam penelitian ini yang diutamakan adalah perlakuan saja, tanpa ada kelompok kontrol (Latipun, 2015: 68). 
Teknik pengumpulan data dalam penelitian ini meliputi:

1. Wawancara, dilakukan saat pra penelitian untuk memperoleh informasi mengenai fenomena masalah yang dialami siswa di SMP Negeri 10 Kendari selama satu pekan.

2. Angket Screening, dilakukan saat pra penelitian kepada siswa yang bertujuan untuk mendapatkan subjek penelitian.

3. Angket Skala Kecemasan Belajar Matematika, digunakan saat pre test dan post test untuk mengetahui tingkat kecemasan belajar Matematika yang dialami siswa.

Teknik analisis data dalam penelitian ini menggunakan teknik analisis deskriptif presentase dan teknik analisis statistik inferensial. Analisis deskriptif presentase digunakan untuk mengetahui gambaran kecemasan belajar Matematika siswa maka skor akan dikonversikan ke dalam 4 kategori penilaian yaitu terdiri dari: sangat tinggi, tinggi, rendah, sangat rendah.

Analisis statistik inferensial dilakukan untuk menguji hipotesis dengan menggunakan statistik non parametric yaitu dengan wilcoson signed rank test. Hal ini untuk mengetahui perbedaan skor kecemasan belajar Matematika siswa pada saat sebelum diberikan treatment (pre test), dan sesudah diberikan treatment (post test). Uji jenjang bertanda Wilcoxon dapat didasarkan pada sampel kecil ( $\mathrm{n} \leq 25)$ dengan taraf siginifikan 0,05, 0,02 dan 0,01 (Sugiyono, 2016). Adapun rumusan bentuk hipotesis yang diajukan adalah:

1. Jika $\mathrm{H}_{\mathrm{o}}$ diterima berarti layanan bimbingan kelompok tidak dapat mengatasi kecemasan belajar Matematika siswa SMP Negeri 10 Kendari secara signifikan.

2. Jika $\mathrm{H}_{\mathrm{a}}$ diterima berarti ayanan bimbingan kelompok dapat mengatasi kecemasan belajar Matematika siswa SMP Negeri 10 Kendari secara signifikan.

Dengan demikian kriteria pengujian hipotesis adalah jika $\mathrm{P}_{\text {value }}<\alpha(0,05)$ maka $\mathrm{H}_{\mathrm{a}}$ diterima dan $\mathrm{H}_{\mathrm{o}}$ ditolak.

\section{Hasil Penelitian dan Pembahasan Hasil Penelitian}

Analisis deskriptif skor pre test

Sebelum diberikan perlakuan, 8 orang siswa sebagai subjek diberikan angket pre test untuk mengetahui gambaran kecemasan belajar Matematika siswa sebagaimana pada tabel berikut:
Tabel 1

Skor Pre Test Kecemasan Belajar Matematika

\begin{tabular}{|c|c|c|c|}
\hline No & Subjek & Pre Test & Kategori \\
\hline 1 & AA & 160 & Tinggi \\
\hline 2 & AR & 152 & Tinggi \\
\hline 3 & AFT & 143 & Rendah \\
\hline 4 & DMK & 147 & Rendah \\
\hline 5 & EP & 150 & Tinggi \\
\hline 6 & PS & 167 & Tinggi \\
\hline 7 & SNT & 159 & Tinggi \\
\hline 8 & WEIA & 133 & Rendah \\
\hline \multicolumn{3}{|c|}{ Jumlah } & \multicolumn{3}{|c|}{151,375} \\
\hline \multicolumn{3}{|c}{ Rata-rata } & \multicolumn{3}{c}{} \\
\hline
\end{tabular}

Berdasarkan tabel di atas maka siswa kelas VIII.7 mengalami kecemasan belajar Matematika berjumlah 5 siswa kategori tinggi dan 3 siswa kategori rendah dengan rata-rata skor 151,375 selanjutnya diberikan treatment yaitu layanan bimbingan kelompok dalam upaya mengurangi kecemasan belajar Matematika yang dialami siswa.

\section{Analisis deskriptif skor post test}

Gambaran kecemasan belajar Matematika siswa kelas VIII.7 SMP Negeri 10 Kendari setelah diberikan perlakuan berupa layanan bimbingan kelompok dapat diketahui berdasarkan hasil analisis angket kecemasan belajar Matematika seperti pada tabel berikut:

Tabel 2

Skor Post Test Kecemasan Belajar Matematika

\begin{tabular}{|c|c|c|c|}
\hline No & Subjek & Post Test & Kategori \\
\hline 1 & AA & 138 & Rendah \\
\hline 2 & AR & 142 & Rendah \\
\hline 3 & AFT & 123 & Rendah \\
\hline 4 & DMK & 131 & Rendah \\
\hline 5 & EP & 130 & Rendah \\
\hline 6 & PS & 139 & Rendah \\
\hline 7 & SNT & 136 & Rendah \\
\hline 8 & WEIA & 107 & Rendah \\
\hline \multicolumn{3}{|c|}{ Jumlah } & \multicolumn{3}{|c|}{1046} \\
\hline \multicolumn{3}{|c|}{ Rata-rata } & \multicolumn{3}{|c|}{} \\
\hline
\end{tabular}

Berdasarkan tabel di atas skor kecemasan belajar Matematika siswa kelas VIII.7 SMP Negeri 10 Kendari menurun dengan rata-rata 130,75 . Berdasarkan hasil analisis data maka dapat diperoleh gambaran kecemasan belajar 
Matematika siswa kelas VIII.7 SMP Negeri 10 Kendari sebelum dan sesudah pemberian layanan bimbingan kelompok. Adapun analisis tersebut dapat dilihat pada tabel berikut:

Tabel 3

Perbandingan Skor Pre Test dan Post Test

\begin{tabular}{|c|c|c|c|c|}
\hline No & Subjek & Pre Test & Post Test & \% Penurunan \\
\hline 1 & AA & 160 & 138 & $7,38 \%$ \\
\hline 2 & AR & 152 & 142 & $3,40 \%$ \\
\hline 3 & AFT & 143 & 123 & $7,51 \%$ \\
\hline 4 & DMK & 147 & 131 & $5,75 \%$ \\
\hline 5 & EP & 150 & 130 & $7,14 \%$ \\
\hline 6 & SNT & 167 & 139 & $9,15 \%$ \\
\hline 7 & PS & 159 & 136 & $7,79 \%$ \\
\hline 8 & WEIA & 133 & 107 & $10,83 \%$ \\
\hline \multicolumn{6}{|c|}{ Rata-rata } & $\mathbf{1 5 1 , 3 7}$ & $\mathbf{1 3 1 , 7 5}$ & $\mathbf{7 , 3 6 \%}$ \\
\hline
\end{tabular}

Dari hasil perbandingan skor di atas, kecemasan belajar Matematika siswa SMP Negeri 10 Kendari menurun terlihat dari persen (\%) penurunan kecemasan belajar Matematika siswa yaitu sebesar 7,36\%.

Selanjutnya, hasil analisis data statistik bahwa berdasarkan hasil perhitungan uji Wilcoxon Signed Rank Test pada tabel Test Statistics diperoleh nilai Asymp. Sig. (2-tailed) $=0,012<$ 0,05 , artinya $\mathrm{H}_{\mathrm{o}}$ ditolak dan $\mathrm{H}_{\mathrm{a}}$ diterima. Dengan kata lain layanan bimbingan kelompok dapat mengatasi kecemasan belajar Matematika secara signifikan.

\section{Pembahasan}

Kecemasan terhadap mata pelajaran Matematika tidak bisa dipandang sebagai hal biasa, karena ketidakmampuan siswa dalam beradaptasi pada pelajaran Matematika menyebabkan siswa kesulitan dalam memahami materi pelajaran, membuat siswa tidak mampu menyelesaikan soalsoal dan kemudian menghindari kelas Matematika dan pada akhirnya menyebabkan hasil belajar dan prestasinya menurun. Dalam bimbingan dan konseling, terdapat berbagai macam layanan yang dapat dilakukan untuk mengatasi masalah siswa seperti masalah di atas yaitu kecemasan belajar Matematika, salah satunya adalah layanan bimbingan kelompok.

Layanan bimbingan kelompok dapat mengatasi kecemasan belajar Matematika siswa kelas VIII.7 SMP Negeri 10 Kendari sebagaimana yang diperoleh sebagai hasil dalam penelitian ini bahwa kecemasan belajar Matematika siswa mengalami penurunan sebesar $7,47 \%$ setelah diberikan perlakuan. Hasil penelitian ini juga diperkuat dengan hasil analisis data statistik bahwa berdasarkan hasil perhitungan uji Wilcoxon Signed Rank Test pada tabel Test Statistics diperoleh nilai Asymp. Sig. (2-tailed) $=0,012<0,05$, artinya $\mathrm{H}_{\mathrm{o}}$ ditolak dan $\mathrm{H}_{\mathrm{a}}$ diterima. Dengan kata lain bahwa layanan bimbingan kelompok dapat mengatasi kecemasan belajar Matematika.

Hasil penelitian ini mendukung hasil penelitian yang dilakukan Tuyanto (2011) tentang efektifitas bimbingan kelompok dengan teknik diskusi kelompok untuk mengurangi kecemasan dalam menghadapi ujian nasional pada siswa SMA XII Negeri 1 Wonosegoro. Hasil penelitian tersebut menunjukkan bahwa bimbingan kelompok dengan teknik diskusi teman sebaya dapat mengurangi kecemasan dalam menghadapi ujian nasional pada siswa SMA XII Negeri 1 Wonosegoro. Penelitian Yarah, dkk. (2018) menunjukkan bahwa bimbingan kelompok efektif untuk mengurangi kecemasan pada siswa. Anggota dalam kelompok dapat memberikan saran pemecahan masalah yang dihadapi yang belum terpikirkan oleh individu bermasalah.

Menurut Mammarella, Caviola dan Dowker (2018: 5) kecemasan Matematika melibatkan komponen afektif, emosionalitas, kognitif dan kekhawatiran yang disadari. Adapun Cooke (dalam Syafri, 2017: 62) menyebut ada 4 aspek yang menyebabkan kecemasan belajar pada siswa yaitu mathematics knowledgel understanding (pemahaman), somatic (somatik), cognitive (kognitif) dan attitude (sikap).

Hasil pengelolaan data aspek mathematics knowledgel understanding (pemahaman Matematika) menurun sebesar 2,75\%. Aspek mathematics knowledgel understanding (pemahaman Matematika) menurut Cooke (dalam Syafri, 2017) berkaitan dengan hal-hal seperti munculnya pikiran bahwa dirinya tidak cukup tahu tentang Matematika. Aspek somatic (somatik) menurun sebesar 8,79\%. Aspek somatik menurut Cooke (Syafri, 2017) berkaitan dengan perubahan pada keadaan tubuh, misalnya tubuh berkeringat atau jantung berdebar cepat, serta mengalami ketegangan dan mual (Feiberg dalam Whyte dan Anthony, 2012).

Selanjutnya, Aspek cognitive (kognitif) menurun sebesar 7,83\%. Aspek kognitif menurut Cooke (dalam Syafri, 2017) berkaitan dengan perubahan kognitif seseorang ketika berhadapan dengan Matematika, seperti tidak dapat berpikir jernih, menjadi lupa hal-hal yang biasa diingat, 
serta pikiran menjadi kosong (blank) dan penghindaran (Feiberg dalam Whyte dan Anthony, 2012). Aspek Attitude (sikap) menurun sebesar 6,98\%. Aspek sikap menurut Cooke (dalam Syafri, 2017) menimbulkan sikap seperti tidak percaya diri atau enggan melakukan sesuatu yang berkaitan dengan Matematika, serta takut terlihat bodoh dan kehilangan harga diri.

\section{Kesimpulan dan saran \\ Kesimpulan}

Berdasarkan hasil analisis data yang dilakukan, maka dapat diperoleh gambaran kecemasan belajar Matematika siswa di SMP Negeri 10 Kendari sebelum dan sesudah diberikan treatment menunjukkan perubahan. Adapun hasil analisis data tersebut diketahui bahwa 5 orang siswa sebelum diberikan treatment tingkat kecemasan belajar Matematika siswa masuk dalam kategori tinggi dengan rata-rata 151,375 dan setelah diberikan layanan bimbingan kelompok terjadi penurunan menjadi 131,75 atau $7,36 \%$ dan masuk kategori rendah. Selanjutnya, analisis statistik inferensial untuk menguji hipotesis menggunakan statistic non parametric yaitu wilcoxon signed rank test pada taraf signifikan $\alpha=$ 0.05 diperoleh $\mathrm{P}_{\text {value }}=0.012 . \mathrm{P}_{\text {value }}<\alpha \quad(0.012<$ 0.05) dengan demikian $\mathrm{H}_{\mathrm{o}}$ ditolak dan $\mathrm{H}_{\mathrm{a}}$ diterima. Maka dapat disimpulkan bahwa layanan bimbingan kelompok dapat mengatasi kecemasan belajar Matematika siswa SMP Negeri 10 Kendari.

\section{Saran}

\section{Bagi Guru BK}

Hasil penelitian ini bisa dijadikan bahan masukan dalam peningkatan layanan bimbingan dan konseling khususnya dalam memberikan layanan bimbingan kelompok dalam mengatasi kecemasan belajar Matematika siswa.

2. Bagi Siswa

Terapkanlah materi yang telah didapatkan melalui bimbingan kelompok agar tidak mengalami kecemasan saat belajar Matematika dan perbanyaklah mengerjakan latihan soal-soal seperti tips yang telah disampaikan.

3. Bagi Peneliti Selanjutnya

a. Dalam penelitian ini untuk mengetahui data tentang kecemasan belajar Matematika siswa digunakan wawancara dan angket sebagai metode pengumpulan data. Oleh sebab itu hendaknya peneliti selanjutnya menambahkan metode observasi sebagai salah satu metode pengumpulan data untuk mengetahui kecemasan belajar Matematika siswa.

b. Peneliti selanjutnya diharapkan mampu menampilkan materi layanan bimbingan lebih menarik perhatian siswa yang didukung dengan sarana dan prasarana kegiatan yang memadai.

\section{Daftar Pustaka}

Anita, Ika Wahyu. (2014). Pengaruh Kecemasan Matematika (Mathematics Anxiety) Terhadap Kemampuan Koneksi Matematis Siswa SMP. Jurnal Ilmiah Program Studi Matematika STKIP Siliwangi Bandung. Vol.3 No.1.

Aunurrofiq \& Junaedi, Iwan. (2017). Kecemasan Matematika Siswa dalam Menyelesaikan Soal-Soal Pemecahan Masalah. Journal of Mathematics Unnes.

Baini, Rahmawati Saharuddin. (2018). Penerapan Layanan Informasi dengan Teknik Fun Game untuk Mengurangi Kejenuhan Belajar Siswa SMP Negeri 5 Kendari. Skripsi Universitas Halu Oleo.

Handayani, Dwi Shinta. (2016). Pengaruh Konsep Diri dan Kecemasan Siswa terhadap Pemahaman Konsep Matematika. Jurnal Program Studi Teknik dan Informatika. Universitas Indraprasta PGRI. Vol.6 No.3

Hartatik \& Fifi Khoirul Fitriyah. (2017). Identifikasi Kecemasan Matematika pada Mahasiswa Program Studi Pendidikan Guru Sekolah Dasar. Jurnal Bimbingan dan Konseling Indonesia. Universitas Nahdlatul Ulama Surabaya. Vol.2 No.2.

Hartinah, Sitti. (2009). Konsep Dasar Bimbingan Kelompok. Bandung: PT Refika Aditama.

Lwin, dkk. (2008). Cara Mengembangkan Berbagai Komponen Kecerdasan. Jakarta: PT Indeks.

Latipun. (2015). Psikologi Eksperimen. Malang: UMM Press.

Mammarella, C. Irene, Sara Caviola \& Ann Dowker. (2018). Mathematics Anxiety What is Known and what is still to be Understood. London and New York: Routledge. 
Rahman, Nursalam, \& Tahir. (2015). Pengaruh Kecemasan dan Kesulitan Belajar Matematika Terhadap Hasil Belajar Matematika Pada Siswa Kelas X MA Negeri 1 Watampone Kabupaten Bone. E-Jurnal Matematika dan Pembelajaran. Vol.3 No.1.

Sarwono, Sarlito Wirawan. (2008). Pengantar Psikologi Umum. Jakarta: PT Raja Grafindo Persada.

Syafri, Santri Fatrima. (2017). Ada Apa Dengan Kecemasan Matematika?. E- journal of Mathematics Education IKIP Veteran Semarang. Vol.1 No.1.

Sugiyono. (2016). Metode Penelitian Kombinasi (Mixed Methods). Bandung: Alfabeta.

Sugiyono. (2017). Statistika untuk Penelitian. Bandung: Alfabeta.

Whyte \& Anthony, Glenda. (2012). Math Anxiety: The Fear Factor in the Mathematics Classroom. New Zealand Journal of Teachers' Works Vol. 9 Issue 1. 